\title{
Empresarios y producción espacial en torno al club de Fútbol León en México
}

Entrepreneurs and space production around club de Fútbol León in Mexico

Empreendedores e produção espacial ao redor do club de Fútbol León no México

\section{Jonathan Montero Oropeza}

Universidad de Guanajuato y UNAM

E-mail: jonathanmon06@gmail.com

\section{Resumen}

En el presente trabajo se analiza desde la geografía humana el proceso de producción espacial en torno al futbol convertido en negocio empresarial en León, Guanajuato. Se hace hincapié en las relaciones de los empresarios inmersos en el futbol profesional y su impacto en la producción espacial, las relaciones Estado-Empresa y el proceso identitario a través del futbol en León.

Palabras clave: Empresarios, Espacio, Futbol, León

\section{Abstract}

In the present study analyzed from human geography the production process space around football developed business in Leon, Guanajuato. Emphasis in the relationships of employers engaged in professional 
football and its impact on the spatial production, the relationship between State-Company, and the identity process through soccer in Leon.

Keywords: Entrepreneurs, Space, Soccer, León

\section{Resumo}

No presente trabalho, o processo de produção espacial do futebol, transformado em um negócio em León, Guanajuato, é analisado a partir da geografia humana, com ênfase nas relações de empreendedores imersos no futebol profissional. e seu impacto na produção espacial, nas relações Estado-Empresa e no processo identitário através do futebol em León.

Palavras chave: Empreendedores, espaço, futebol, León

$$
* * *
$$

\section{Introducción}

Este estudio inició con motivo de los estudios de Maestría titulado El proceso de producción espacial en torno a la empresa del futbol en León, Guanajuato (1943-2014). En las siguientes líneas, se analiza el papel de diversos actores sociales empresariales que se relacionaron con el manejo administrativo de un equipo de futbol profesional en México, el Club León. El objetivo radica en comprender por qué diversos empresarios buscaron ser protagonistas de las relaciones de poder espaciales para aumentar su capital económico y el volumen de su capital social a través de su intervención en la propiedad de una asociación deportiva.
Un escrito de este tipo se justifica debido a la relevancia que tiene el futbol en su versión profesional en León, Guanajuato, y en México, tanto en el ámbito económico, como en el aspecto identitario. En ese sentido, vale la pena reconstruir el proceso espacio-temporal del Club León, para desentrañar los vínculos Estado-Empresa y comprender cómo las élites empresariales configuran el espacio geográfico mediante una actividad deportiva altamente lucrativa, lo cual incluso llevó a un sector del empresariado y del Ayuntamiento de León a mantener una disputa legal por el estadio Nou Camp, lo cual revela las relaciones de poder que mantienen los actores sociales hegemónicos de una ciudad media mexicana.

Como sustento teórico se retoma la perspectiva del geógrafo inglés David Harvey, puesto que permite analizar las relaciones de poder en el espacio y sus implicaciones en el ámbito urbano. Su posición será de utilidad para interpretar las acciones y alianzas de los empresarios que fungieron como propietarios del Club León en diferentes periodos.

La metodología que sirvió como base a esta investigación, tuvo su primera etapa en el Archivo Histórico del Municipio de León (AHML), para indagar sobre los diferentes dueños del Club León. Posteriormente, se realizaron una serie de entrevistas semiestructuradas a actores sociales involucrados con el medio futbolístico y empresarial local, para desentrañar el proceso de producción espacial y las relaciones de poder sobre este equipo de futbol profesional.

En el primer apartado, se presenta el contexto geográfico de la ciudad de León, con el propósito de mostrar las particularidades de esta ciudad mexicana, sus transformaciones espacio-temporales y el papel que en ese proceso tuvo la élite empresarial local y la clase política. En el segundo punto, se explica brevemente el contexto histórico-geográfico sobre cómo surgió el Club de Futbol León.

El tercer apartado plasma las implicaciones espaciales de la construcción del estadio Nou Camp, para mostrar las relaciones terri- 
toriales Estado-Empresa y la importancia que tuvieron en la ciudad de León los megaeventos deportivos que ahí se albergaron. En el cuarto punto, se describe cómo ante las crisis de la economía mexicana, los empresarios leoneses dejaron de solventar económicamente al Club León y de qué manera diversos empresarios foráneos tomaron las riendas del equipo.

\section{Contexto geográfico de León, guanajuato, México}

La ciudad de León se localiza en el estado de Guanajuato, en lo que se conoce como la región del Bajío. En términos geográficos e históricos, el Bajío se asocia más a Guanajuato que a las zonas de los otros estados que también conforman la región: Michoacán, Jalisco y Querétaro (Chávez, 2012: 21). León es el foco económico, político y empresarial del Bajío, debido a las industrias zapatera local y automotriz transnacional con las que cuenta, los centros de congresos y convenciones que alberga, los servicios de los ramos hotelero y restaurantero que posee, la oferta educativa de nivel superior (pública y privada) que ofrece, la infraestructura vial que tiene y la conectividad carretera que posee.

León se convirtió en un espacio geoestratégico entre Ciudad de México y Guadalajara, Jalisco, las dos ciudades más importantes de México. Además, mantiene profundos vínculos económicos y culturales con los Altos de Jalisco, una región mexicana que se identifica por su tradición ganadera y el conservadurismo católico que profesan la mayoría de sus habitantes.

El estado de Guanajuato es una de las pocas entidades federativas en México donde la capital (la ciudad de Guanajuato) no tiene la preponderancia económica y política. De hecho, se puede hablar de Guanajuato como uno de los estados menos centralizados del país. A pesar de esta circunstancia, la infraestructura económica en Guanajuato, se concentra en los municipios de León, Irapuato, Salamanca, Celaya, Guanajuato y San Miguel de Allende.
¿En qué momento León tomó el protagonismo económico y político en el estado de Guanajuato? Hacia mediados del siglo XIX, tras la decadencia de actividad minera, la capital de Guanajuato, la ciudad de Guanajuato, perdió su potencial como espacio económico, mientras León, paulatinamente despuntó como consecuencia de la producción de rebozos, la confección de artículos de piel y las migraciones realizadas por los habitantes de los Altos de Jalisco. Desde inicios y mediados del siglo XX, la capital estatal dejó de ser el espacio focal de la economía guanajuatense. El reconocido escritor mexicano Jorge Ibargüengoitia (1928-1993) hizo alusión a la rivalidad entre ambas ciudades en su novela Estas ruinas que ves. En esa obra, parodia el marco social de Guanajuato y León, a las que cambia el nombre por "Cuévano" y "Pedrones", respectivamente, y señala que mientras los habitantes de la primera se sienten "Atenas" los segundos confunden "lo grandote con lo grandioso".

Cabe resaltar que una peculiaridad de León, es su marcada adscripción al conservadurismo católico, herencia de la guerra cristera (1926-1929) y de las migraciones de los habitantes de los Altos de Jalisco. A la influencia de la Iglesia Católica, hay que añadir que los grupos de poder empresariales y políticos de León conformaron un discurso donde se enaltece la idea de Guanajuato como una de las entidades federativas más representativas del país, donde se gestó la lucha de la Independencia, además del surgimiento en su seno de íconos de la "mexicanidad", como el charro del Bajío y en donde nacieron relevantes intérpretes de la música ranchera, como José Alfredo Jiménez, Jorge Negrete y Flor Silvestre.

León se caracteriza por su vocación industrial en la producción de calzado, por ser la cuna de movimientos sociales identificados con la derecha y la ultraderecha, la profunda religiosidad de sus habitantes, el carácter conservador de la educación, el poco atractivo del electorado por los partidos vinculados con la izquierda y un fuerte sentido de adscripción local. En ese contexto, el equipo de futbol Club León, juega un papel primordial en el proceso identitario al interior del municipio de León. 


\section{Génesis del Club León}

Durante las primeras tres décadas del siglo XX el beisbol y las corridas de toros eran algunos de las principales atractivos que León ofrecía a sus habitantes. Paulatinamente el futbol tomó un papel preponderante, como consecuencia de la organización de equipos auspiciados por las empresas curtidoras y zapateras que emergían en la ciudad, o bien por algunos sacerdotes locales. El objetivo, tanto de los dueños de las fábricas, como de los presbíteros, radicaba en evitar o retirar a los jóvenes y obreros de vicios, para así mantener un estado físico y mental saludable, en armonía con el higienismo social y los preceptos morales católicos.

Hacia 1942, el IX Campeonato Nacional de futbol se celebró en Irapuato, Guanajuato, ciudad que albergaba un moderno estadio de concreto, a diferencia de la mayoría en México, que eran de madera, por ese entonces. La Selección de Guanajuato - que estaba encabezada por varios futbolistas de la ciudad de León- resultó la ganadora del torneo al derrotar a la Selección de Jalisco. En ese año, se reavivó la polémica concerniente a si el Campeonato Nacional de futbol mexicano, debía continuar en su formato amateur o profesionalizarse. En realidad, eran torneos de corte semiamateur, puesto que los futbolistas recibían remuneraciones económicas por jugar; además en los estadios se cobraba la entrada y se vendían bebidas y botanas, es decir ya existía una comercialización en torno al futbol. El primer torneo de futbol profesional en México se efectuó en 1943.

La Federación Mexicana de Futbol (Femexfut), admitió al representativo de la ciudad de León, el cual hasta ese momento se llamaba Unión de Curtidores, equipo auspiciado por futbolistas de corte amateur. La Femexfut admitió al equipo, bajo ciertas condiciones: contar con una cancha reglamentaria para la celebración de los partidos profesionales; constituir una Asociación Civil no menor a 150 socios; y cambiar el nombre del equipo por el de León. Para la Femexfut resultaba atractivo que los conjuntos futbolísticos de ciudades relevantes llevaran el topónimo del espacio geográfico que representaban, muy al estilo del futbol europeo o de los deportes estadunidenses.

De tal manera, una serie de empresarios leoneses aprovecharon la oportunidad para administrar esa asociación futbolística y quitar el nombre de Unión de Curtidores -referente a una de las actividades laborales y gremiales de mayor tradición en el municipio- para colocarle el nominativo de la ciudad. Así surgió el Club León, cuando empresarios zapateros y comerciantes locales, conformaron una Asociación Civil para sostener colectiva y económicamente al equipo, el cual fue aceptado para participar en la liga mexicana en 1944. El Club León, jugó sus primeros partidos en el estadio Patria y posteriormente en el estadio Enrique Fernández Martínez, coso deportivo edificado en 1945, como parte de una promesa del gobernador a los jugadores leoneses que participaron en la Selección Guanajuato campeona del torneo amateur en 1942. Bourdieu (1991) plantea que el poder simbólico es bien representado en cuanto a los nombres propios se refiere, porque revelan muchas cuestiones sociales y culturales que nos forman como individuos. En ese contexto es que debe comprenderse que el nombre del estadio, llevara el nombre del gobernador en turno, como una referencia así mismo.

Posteriormente, se conformó otro equipo en la ciudad, el San Sebastián (nombre que aludía al santo patrono de León). Sus propietarios, edificaron un estadio denominado La Martinica, el cual en 1947, pasó también a ser el espacio de los partidos como local del Club León. El León, se volvió un equipo protagonista del futbol mexicano, puesto que en su nómina figuraban varios de los mejores jugadores mexicanos de la época y los más destacados futbolistas extranjeros que llegaron a México en ese momento. Esta situación no era fortuita.

Durante la Segunda Guerra Mundial (1939-1945), el empresariado zapatero se favoreció debido a la demanda de calzado que se requería en Estados Unidos, puesto que este país al involucrarse en el conflicto bélico, abrió sus fronteras para atender la demanda interna de distintos pro- 
ductos, como los zapatos y las botas militares, por lo que en México se intensificó su fabricación y exportación. Además, durante los sexenios presidenciales de Manuel Ávila Camacho (1940-1946), Miguel Alemán Valdés (1946-1952) y Adolfo Ruiz Corties (1952-1958) como parte de un discurso mundial vinculado a la modernidad occidental, el Estado mexicano impulsó como una de sus políticas "calzar al país", es decir, que todos los ciudadanos mexicanos accedieran al uso de zapatos en su indumentaria cotidiana, aspecto visto como un elemento de progreso y avance social.

Este contexto de bonanza económica de los empresarios zapateros, sirvió para solventar al Club León mediante la Asociación Civil que lo auspiciaba monetariamente, por lo que se diseñó un equipo competitivo. Los resultados no tardaron en llegar, puesto que el Club León logró los campeonatos en las temporadas 1947-48, 1948-49, 1951-52 y 1955-56, lo cual lo convirtió en el equipo hegemónico del momento y colocó a la ciudad zapatera dentro del imaginario del aficionado al futbol en México. En ese entonces, el equipo tomó el mote con el que se conocía a los leoneses en México, los "Panzas Verdes", debido a las manchas en los delantales de los obreros del sector cuero-calzado que trabajaban en la ciudad.

\section{La construcción de un espacio deportivo: el estadio Nou Camp}

La Asociación Civil del Club León, en busca de generar mayores ganancias económicas a través del equipo y aumentar el volumen del capital social de los empresarios involucrados en su administración, gestionó en 1965, a través de dos de sus miembros, Manuel Ortega y Adolfo Sánchez López, la realización de un nuevo estadio, y así obtener mayores recursos económicos para la institución. El entonces gobernador de Guanajuato entre 1961 y 1967, Juan José Torres Landa, realizó la donación de una serie de terrenos para la construcción del nuevo estadio y detonar la urbanización en esa zona de la ciudad.
El nuevo estadio se contempló dentro del "Plan Guanajuato", un proyecto urbano cuya intención era dotar de equipamiento vial, industrial, educativo y deportivo al estado, y que tenía como objetivo transformar a una entidad federativa especialmente rural en un espacio de ciudades medias interconectadas. Por ello, en términos generales, el "Plan Guanajuato", tuvo la aceptación de la ciudadanía, la Iniciativa Privada y el Gobierno Federal, puesto que en el discurso oficial del momento, los procesos de urbanización e industrialización se percibían como elementos de modernidad. En su Primer Informe de Gobierno, Torres Landa, señaló:

"Desde hace casi cinco siglos, la estructura social de este mundo viene transformándose de agraria en industrial. La base de este proceso consiste en que la agricultura va siendo sustituida gradualmente por la industria como eje de la vida económica" (Torres Landa, 1961: 19).

El discurso es paralelo a la tendencia del entonces Presidente de México, Adolfo López Mateos, por disminuir la inversión pública hacia el campo y aumentar la industrialización del país, puesto que se percibía a ésta, como un elemento de modernidad y progreso. En ese contexto, se construyó en León el Boulevard López Mateos. A partir del decreto 74 del Congreso del Estado, se aprobó la construcción de esta vialidad que encarnó una transformación urbana en la ciudad de León (García, 2010: 97).

En consecuencia, la localización del nuevo estadio, se propuso en lo que eran los límites espaciales de la zona urbana de León, a un costado del novedoso boulevard López Mateos y de las instalaciones de la Feria de León, inauguradas en 1962. En agosto de 1965 se inició la edificación del estadio Nou Camp, a cargo de la empresa ARVA S.A., una empresa inmobiliaria jalisciense.

El estadio Nou Camp se inauguró el $1^{\circ}$ febrero de 1967, en un torneo al que fueron invitados los equipos River Plate de Argentina y Santos de Brasil, este último contaba entre sus jugadores con la estrella Edson Arantes do Nascimento "Pelé". El caso de la construcción del estadio 
Nou Camp, revela cómo la producción del espacio mediante la dotación de infraestructura, permite a los involucrados intervenir territorialmente y generar diferencias geográficas que permitan consolidar sus intereses políticos y económicos. El gobernador Torres Landa, consiguió entre varios sectores de la ciudadanía legitimación social, tras la generación de un elemento espacial que marcó las pautas de urbanización en el municipio de León. La directiva del Club León obtuvo un inmueble deportivo propio y mejoró su situación económica a corto plazo. La inmobiliaria ARVA, logró ganancias económicas y consolidó su reputación como empresa constructora. El proyecto fue bien recibido por la ciudadanía, puesto que la idea se promocionó como una necesidad del Club León, uno de los elementos de identidad territorial de la ciudad; además al considerar el coso deportivo dentro del "Plan Guanajuato", el proyecto se percibió como un catalizador de la urbanización en el municipio.

El espacio no es estático, cambia constantemente su fisonomía, su apariencia y junto con ello, sus relaciones. La construcción de un estadio por lo regular redefine las funciones de una zona de la ciudad y puede ser un mecanismo para que ésta se inserte en un proceso de competitividad (regional, nacional o incluso global), debido a los espacios complementarios que se originan. Depende de la capacidad de los diferentes actores sociales para generar la legitimidad social del proyecto, la infraestructura vial y la accesibilidad para desplazarse al inmueble, el impacto ecológico de la obra, la aplicación de tecnología en la construcción y los usos alternativos que puede tener un estadio, como conciertos, mítines políticos o eventos religiosos.

En este sentido, hay que recordar que el espacio no es un soporte de la realidad donde se localizan elementos, ni mucho menos un simple espejo de la sociedad, como se pretende analizar desde la concepción espacial empirista y la del reflejo. Existe otra manera de interpretar el espacio, comprendiendo a éste como un producto social dentro de un sistema de relaciones sociales (Ortega, 2000: 362). La construcción de un estadio ocasiona que una ciudad, o más bien dicho, una región al interior de la ciudad, modifique su aspecto, puesto que se originan a su alrededor espacios complementarios que repercuten en los procesos territoriales de sus habitantes, a la vez que los ciudadanos depositan ahí sus lealtades, lo cual configura en el espacio geográfico prácticas sociales y relaciones de poder.

Para David Harvey, existe un papel cambiante de la espacialidad en la sociedad contemporánea, puesto que los capitalistas se muestran, cada vez con mayor sensibilidad a las cualidades espacialmente diferenciadas dentro de la geografía mundial (Harvey, 1989: 326, 334). Por tanto, es posible que los poderes que controlan esos espacios los modifiquen con el fin de ser más atractivos para el capital, puesto que la identidad se convierte en un tema importante porque cada sujeto ocupa un lugar de individuación (Ibid. 334).

En este tenor se debe considerar el papel del estadio Nou Camp en los Juegos Olímpicos México 68 y los Mundiales de Futbol de 1970 y 1986. La celebración de siete partidos de futbol en León durante los Juegos Olímpicos México 68, permitió a las élites empresariales y políticas locales percatarse de las ganancias económicas que arrojaba el arribo de turistas. Un año después, en 1969 y previo al Mundial México 1970, se inauguró en León una nueva Terminal de Autobuses. Posteriormente, el Mundial de México 1970 fue exitoso para las élites políticas y económicas de León.

Otro aspecto que es importante resaltar es que para el Mundial México 1970 se eligieron a cinco urbes como sede: Ciudad de México, Guadalajara, Puebla, Toluca y León. A diferencia de Guadalajara, Puebla y Toluca, León no era capital estatal, lo cual demostraba la hegemonía empresarial, económica y política de la ciudad, la cual albergó siete partidos del certamen futbolístico. Para el Mundial México 1986, León repitió como sede para el megaevento, mientras que otra ciudad guanajuatense, Irapuato, también se designó como asiento del certamen, lo cual revela la capacidad de gestión de las elites empresariales guanajuatenses para conformar a través del futbol profesional, espacios 
atractivos para el gran capital y para el máximo organismo regulador del balompié en escala global, la Fédération Internationale de Football Association (FIFA, por sus siglas en francés).

Se debe agregar que la celebración de los tres megaeventos deportivos, permitió a las élites empresariales leonesas percatarse de la atracción de recursos monetarios como consecuencia de la actividad turística. De hecho, previo a los tres certámenes, creció el número de hoteles en la ciudad, lo cual modificó la imagen urbana de León e implicó el afianzamiento de desarrollos geográficos desiguales en la urbe, mediante la dotación de infraestructura en algunas regiones específicas al interior de la ciudad.

\section{Nuevos propietarios del club León y disputas espaciales en torno al estadio Nou Camp}

Hacia mediados de la década de los setenta y a lo largo de los ochenta y los noventa, del siglo XX, las empresas del sector cuero-calzado en León experimentaron una debacle financiera. En primer término, hubo una crisis de insumos para la producción. Además, muchas compañías zapateras tuvieron dificultades en la transición generacional de la administración de sus empresas. Se suma también, la dificultad que tuvieron para adaptarse al nuevo proceso de globalización contemporánea; paulatinamente la introducción más frecuente a México de calzado procedente de China y Vietnam, afectó a las pequeñas, medianas y grandes factorías de calzado de León. Al ser más barato, un amplio sector de consumidores se declinó por adquirir los productos asiáticos. A estos factores debe agregarse las crisis económicas que se vivieron en México durante 1976, 1982 y 1994.

La conjugación de factores socioeconómicos locales, nacionales y globales, condujeron al empresariado leonés a reestructurar sus estrategias de acción empresarial. La administración de la Asociación
Civil Club León, no fue la excepción. La disminución en la tasa de ganancia de las empresas zapateras y de distribución de calzado, se manifestó en la debacle deportiva del equipo cuando éste descendió a la segunda categoría del balompié mexicano en 1987.

Ante esta compleja situación, los empresarios que financiaban y encabezaban al Club León, decidieron transformar la personalidad jurídica del equipo hacia una Sociedad Anónima, al vender sus acciones a un único capitalista. Después de un breve periodo en que empresarios agroindustriales y del calzado deportivo procedentes de San Francisco del Rincón, Guanajuato, administraran al Club León, en una transacción poco clara, el empresario y político leonés Roberto Zermeño Vargas se hizo de la propiedad del equipo, constituyendo así al Club León como Sociedad Anónima.

Después del ascenso a la Primera división en 1990, bajo el manto de Zermeño, el Club León logró el campeonato del máximo circuito del futbol mexicano en 1992. Dos años después, en 1994, Zermeño transfirió el equipo al empresario inmobiliario Valente Aguirre Meza, quien fungió como propietario del Club León hasta 1999, cuando aceptó una oferta realizada por el propio Zermeño para que este tomará nuevamente la propiedad del equipo. Roberto Zermeño administró al equipo entre 1999 y 2002, año en que descendió a la Segunda División.

Tras el fracaso en 2002, Zermeño vendió al Club León al inmobiliario argentino Carlos Ahumada Kurtz. Este empresario adquirió al equipo, como una manera de acercarse al entonces Presidente de México Vicente Fox Quesada, simpatizante de los "Panzas Verdes". Sin embargo la Femexfut le quitó la propiedad de la franquicia, tras los escándalos de corrupción en que se vio envuelto el empresario, cuando él mismo evidenció una serie de videos en los que otorgaba grandes sumas de dinero a servidores públicos para ser favorecido en las licitaciones de obras en la Ciudad de México. 
Tras el bochornoso suceso conocido en México como los “videoescándalos", el Grupo Pegaso, vinculado al sector de las telecomunicaciones adquirió la propiedad del Club León. Tras múltiples fallidos intentos por ascender a Primera División y el rechazo de los aficionados al proyecto de este conglomerado empresarial, en el año 2009 vendieron la franquicia a un grupo de inversionistas procedentes de Torreón, Coahuila, la familia Batarse, quienes se especializan en comercializar calzado, ropa y artículos electrónicos. La familia Batarse era nueva en el negocio del futbol profesional y tras las cuantiosas pérdidas económicas se deslindaron del equipo y lo vendieron al Grupo Pachuca en 2010.

El Grupo Pachuca es un conglomerado empresarial, con base en el estado de Hidalgo y cuyo Presidente es Jesús Martínez Patiño. Las unidades de negocio de este grupo, se basan en la propiedad y el manejo administrativo de equipos de futbol, entre los cuales se encuentran Tuzos de Pachuca, Club León, Mineros de Zacatecas y Coyotes de Tlaxcala en México y el Everton de Viña del Mar en Chile.

El cimiento de su proyecto inició en 1995. Tras la derrota en la final por ascender a Primera División contra el representativo de Celaya, Martínez Patiño compró al entonces gobernador del estado de Hidalgo, Jesús Murillo Karam, la propiedad de los Tuzos de Pachuca. ${ }^{1}$ A partir de esa transacción, Martínez Patiño generó una serie de contactos en red con el Partido Revolucionario Institucional (PRI), organización política que nunca ha perdido una elección por la gubernatura en el estado de Hidalgo. Las alianzas Empresa-Estado permitieron a Martínez Patiño consoli-

1 Los ojos del mundo voltearon a ver a Murillo Karam, varios años después, en 2014, cuando era el Procurador General de la República en México. Ante la desaparición de 43 estudiantes normalistas en Ayotzinapa, Guerrero, por parte de policías municipales y grupos vinculados al narcotráfico, se desató por parte de la ciudadanía y de organizaciones internacionales una ola de fuertes cuestionamientos ante la escasa transparencia en las investigaciones. Ante las refutaciones en su contra, en una conferencia de prensa mencionó la frase "Ya me cansé", por lo que diversos sectores ciudadanos en México y diversas organizaciones internacionales expresaron su repudio e inconformidad a sus palabras y a su deficiente labor como de Procurador. dar sus negocios y expandirlos geográficamente en la ciudad y producir espacios con la marca de la institución que preside.

En Pachuca, Hidalgo, el Grupo Pachuca es propietario del estadio Hidalgo, inaugurado en 1993, gracias a la donación de terrenos por parte del Ayuntamiento de Pachuca y el estado de Hidalgo. Posteriormente consolidaron el proyecto de la Universidad del Futbol y Ciencias del Deporte, lo cual les brinda la oportunidad de incidir en el ámbito educativo. De su propiedad también es El Museo de Futbol Salón de la Fama, un proyecto el cual avala la FIFA. En el ramo hotelero participan a través del Hotel Camino Real. También auspicia el Tuzo Fórum (Centro de convenciones con capacidad para 2000 personas), un centro comercial denominado Tuzo Plaza y una cadena de artículos deportivos llamada Tuzomanía. En el mundo restaurantero participan mediante Tuzo Tacos, El Buen Bife y Escargotes y poseen franquicias de Domino's Pizza. Además participan en el ámbito inmobiliario a través de Tuzo y Mar-Fas, dos empresas que especulan con terrenos y rentan espacios a Banorte y Home Depot, quienes a su vez son patrocinadores del Club Pachuca.

El éxito del modelo de negocios del Grupo Pachuca, llevó a que desde la adquisición por parte de la familia Martínez, el equipo consiguiera dos campeonatos de Segunda División (1995-1996 e Invierno 1997), seis títulos en la Primera División de México (Invierno 1999, Invierno 2001, Apertura 2003, Clausura 2006, Clausura 2007, Clausura 2016,) cinco torneos de la Liga de Campeones de la Confederación de Norteamérica, Centroamérica y el Caribe de Fútbol (Concacaf) (2002, 2007, 2008, 2009-10, 2016-17) y una Copa Sudamericana (2006).

Para expandir sus negocios e incrementar el volumen de su capital social, el Grupo Pachuca adquirió al Club León en noviembre de 2010 y se nombró como su Presidente a Jesús Martínez Murguía, vástago de Murguía Patiño. Después de diez años en la segunda categoría del futbol mexicano, en mayo de 2012, los "Panzas Verdes" ascendieron a Primera División, lo cual les redituó en la legitimidad por parte de la afición hacia 
el proyecto de la directiva. Ese mismo año, en el mes de septiembre, se anunció que Grupo Pachuca creaba una sinergia con el empresario Carlos Slim, uno de los hombres más ricos del mundo.

Slim había tenido dificultades para entrar el mundo del futbol profesional como propietario de algún equipo, debido a las diferencias con Emilio Azcárraga Jean, dueño de la empresa Televisa y del Club América. Por tanto, el capital económico de Slim sería una pieza fundamental para invertir en el recién ascendido Club León, lo cual en consecuencia, le beneficiaría al Grupo Pachuca, para fortalecer su capital social y económico. Este tipo de alianzas revelan como el capital social de un actor social es útil para quienes forman parte de la asociación, puesto que sus contactos le son redituables al grupo al que pertenece.

Los éxitos deportivos del Club León no tardaron en llegar. El tener una de las nóminas más caras de la Primera División les redituó para ser campeones en los torneos Apertura 2013 y Clausura 2014, contra el Club América y el Club Pachuca, es decir, contra el equipo del rival empresarial de Slim, Emilio Azcárraga Jean, y contra el otro equipo del Grupo Pachuca. La sinergia entre Grupo Pachuca y Slim culminó en septiembre de 2017, cuando el segundo no quiso renovar la sociedad, la cual se pactó por cinco años.

En el año 2018, el Grupo Pachuca anunció "con bombo y platillo" la puesta en marcha del proyecto de un nuevo estadio para el Club León, el cual se tiene previsto inaugurar en el año 2022. La propuesta en la inversión de un novedoso coso deportivo es necesaria para el Grupo Pachuca, puesto que el Nou Camp se encuentra en litigio por su propiedad.

Uno de los antecedentes que se tienen sobre los conflictos por la apropiación del estadio Nou Camp se remiten a 1999, cuando el entonces gobernador de Guanajuato por parte del Partido Acción Nacional (PAN) Vicente Fox Quesada, donó y escrituró una serie de terrenos aledaños al estadio -sin que estos fueran propiedad del estado de Guanajuato- a favor del entonces dueño del Club León, Valente Aguirre. Esta situación causó suspicacia entre los palcohabientes del estadio, encabezados por personajes vinculados al PRI. Este conflicto por la apropiación del estadio Nou Camp, debe entenderse también dentro del marco de confrontación entre el PRI de León y el PAN del estado Guanajuato, puesto que en ese momento Fox se perfilaba como precandidato Presidencial de México.

Un sector de la cúpula empresarial de León, al querer dar un giro al municipio, hacia una ciudad de turismo de negocios y congresos, plantearon la realización del Polifórum León, con el argumento de que éste sería un foco de atracción para eventos empresariales, académicos y sociales. El entonces dirigente del Consejo Coordinador Empresarial de León (CCEL), José Arturo Sánchez, el director del proyecto Polifórum, Gerardo Alderete, y el Presidente del Patronato Polifórum, Roberto Plasencia Saldaña, gestionaron los terrenos circundantes al estadio para la realización de la obra. De esta manera, se habilitaron las hectáreas suficientes en los terrenos aledaños al estadio Nou Camp, para sostener este proyecto. Si bien el equipo de futbol Club León podía devaluarse, no así los terrenos colindantes al inmueble, debido a su posición geoestratégica dentro de la ciudad de León.

El problema legal por el estadio Nou Camp, continuó en el año 2000 cuando Roberto Zermeño Vargas, quien ya era propietario del Club León en ese momento, firmó a favor de que el estadio quedara en manos del Municipio, por lo que renunció a los derechos sobre el inmueble a cambio de unos terrenos contiguos solicitados al Ayuntamiento de León. Como ya se mencionó, Zermeño vendió al Club León a Carlos Ahumada, quien en 2004 fue encarcelado. Zermeño Vargas aprovechó la situación y anunció que un juez le había devuelto la propiedad de la franquicia y el manejo del estadio Nou Camp. En el año 2007, el Ayuntamiento encabezado por el panista Vicente Guerrero Reynoso, adjudicó al Municipio de León como único dueño del estadio Nou Camp, acción que desató un conflicto legal, puesto que el estadio pasó al Ayuntamiento y Zermeño Vargas comenzó a reclamarlo. De hecho, Roberto Adán Zermeño Reyes, 
hijo Zermeño Vargas, interpuso una demanda para reclamar la propiedad del estadio en el año 2011.

A pesar del litigio jurídico por el estadio, durante 2012 y 2013, el Ayuntamiento de León, Grupo Pachuca y empresas patrocinadoras, invirtieron 20 millones de pesos en trabajos de remodelación en el estadio Nou Camp, entre las obras que se realizaron se encuentra la remodelación de las taquillas, los vestidores, la instalación de un circuito cerrado de seguridad y la construcción de una tienda deportiva. El Ayuntamiento de León 2012-2015 (encabezado por la priista Bárbara Botello Santibáñez), otorgó dos millones de pesos para la remodelación del estadio. El punto anterior sirve para percatarnos de las relaciones Empresa-Estado y cómo se regenera un espacio (en este caso deportivo), a pesar de los conflictos por su apropiación. Para la Alcaldesa de León entre 2012 y 2015, Bárbara Botello Santibañez, resultaba importante legitimarse socialmente, por lo cual aprovechó un referente espacial entre los leoneses como el estadio Nou Camp.

Cabe apuntar que en mayo de 2014 se informó al Ayuntamiento de León, que el Juez Tercero de Distrito resolvió a favor de Roberto Adán Zermeño Reyes, la devolución de los derechos de propiedad sobre el estadio Nou Camp. Grupo Pachuca no participa de manera abierta en el conflicto jurídico por la apropiación del estadio, siendo el Ayuntamiento de León quien pugna por la propiedad del inmueble. Puesto que los propietarios del Club León son inversores de considerable envergadura, los diversos Presidentes Municipales que han encabezado el Ayuntamiento buscan consolidar su relación con los dueños del Club León y recuperar la propiedad del estadio Nou Camp, para abrir la inversión a estos grupos capitalistas.

Al fundarse el estadio Nou Camp, en 1967, este se localizaba en los límites de la ciudad, por tanto se convirtió en un espacio que detonó la urbanización por la gran infraestructura que se asienta a su alrededor. Actualmente el estadio, forma parte de un complejo cultural, donde se encuentra el Polifórum, el Domo de la Feria, el Parque Explora, el Fórum
Cultural Guanajuato, el Museo de Arte e Historia de Guanajuato, el Teatro Roberto Plasencia Saldaña y la Universidad de Guanajuato. En este sentido, sale a relucir una vez más, que mientras el estadio es un espacio simbólico para los aficionados, en contraparte para los empresarios y políticos representa la oportunidad de obtener prestigio y legitimidad social y aumentar sus capitales económico, social, simbólico y político.

\section{Consideraciones finales}

La revisión del proceso espacio-temporal del Club León, permite comprender las relaciones de poder empresariales en el futbol mexicano y cómo los actores sociales generan estrategias de acción e intervención. Por ello, en este texto se procuró identificar en León las relaciones espaciales, empresariales, históricas, culturales, económicas y políticas, que configuraron al futbol profesional como un mecanismo para que diversos empresarios locales dieran a este deporte en su versión profesional un uso utilitario, en contraste con la apropiación simbólica de la afición. Hacia las décadas de los cuarenta y cincuenta, los empresarios locales leoneses supieron aprovechar la bonanza económica de sus empresas, al conformar un equipo muy competitivo, el cual forjó en esas dos décadas su pasado dorado.

Uno de los símbolos de la identidad leonesa es el Club León. La época dorada del equipo (entre 1944 y 1960), se encuentra impregnada de la oposición leonesa con respecto al centralismo de la Ciudad de México y la preponderancia de Guadalajara en el occidente del país. Los "Panzas Verdes" representaron en ese momento histórico una vitrina para que la nación mexicana volteara a esta ciudad, la cual empezaba a catapultarse como el corazón de región del Bajío, a la vez que fue un mecanismo para que las élites locales ejercieran un poder discrecional ante la población.

La crisis económica por la que atravesaba el país y las dificultades del sector cuero-calzado al interior de la urbe, afectaron a muchos de los 
empresarios en León, por lo que mantener a un equipo de futbol, se convirtió en una práctica insostenible. Este suceso no es aislado, puesto que en el futbol mexicano desaparecieron las Asociaciones Civiles que administraban a los clubes de futbol profesional y se dio paso a Sociedades Anónimas, las cuales se encuentran respaldadas por las empresas hegemónicas del país, cuyos propietarios buscan en el futbol profesional aumentar la acumulación de sus capitales.

Eso explica que el Club León, desde 1990 y hasta el año 2019, tuviera seis propietarios diferentes, los cuales buscaban más un usufructo económico que fortalecer la cohesión social de los leoneses, con base en este emblemático equipo de futbol. León es una de las ciudades mexicanas más dinámicas, en los ámbitos económico, político, urbano e inmobiliario. Para Harvey (1989: 327) "las ciudades forjan una imagen distintiva y crean un atmósfera del lugar y la tradición, la cual actuará como señuelo tanto para el capital". Por ello, no es casualidad que diversos actores sociales capitalistas participaran como propietarios del equipo, puesto que la ciudad de León y la región del Bajío, les brinda una fuente para aumentar el volumen de su capital social e incrementar las ganancias económicas de sus empresas. En contraparte con la perspectiva utilitaria, los simpatizantes del Club León, profesan una lealtad singular al equipo, a pesar de los fracasos administrativos y futbolísticos que ha tenido la institución, pero que para ellos se equilibra gracias a los campeonatos obtenidos.

Si consideramos que para Claval (2002), el espacio es una traducción de aspiraciones, proyectos y planes para los seres humanos, se comprenderá cómo los dueños del capital aprovechan el deporte profesional para implementar sus proyectos espaciales, sociales y económicos para incidir el territorio. No en vano, Milton Santos (1986), afirma que gran parte de las transformaciones espaciales se llevan a cabo a través de las empresas y de las instituciones que sistematizan la vida social.

Este marco también conduce a comprender las disputas espaciales por el estadio Nou Camp. De acuerdo con Lefebvre (2013: 213), un grupo se apropia de un espacio para servir a sus necesidades y posibilidades. En ese sentido, alrededor del estadio Nou Camp y en sus terrenos circundantes, existen una serie de intereses económicos e inmobiliarios. El alegato jurídico deja de manifiesto cómo los empresarios capitalistas y el Estado ven en el estadio y las instalaciones circundantes un espacio utilitario, ideal para incrementar sus capitales y afianzar su hegemonía; en contraparte con los aficionados al equipo, para los cuales el estadio representa un referente espacial y un espacio simbólico. 


\section{Fuentes bibliográficas:}

Bourdieu, P. (1991). El sentido práctico. Taurus, Madrid.

Chávez, M. (2005). Bajío, Bajíos: unidades territoriales de una región. Regiones. N. ${ }^{\circ} 15$ pp. 117-140. Universidad de Guanajuato: León.

Claval, P.(2002). El enfoque cultural y las concepciones geográficas del espacio. Boletín de la A.G.E.N. Número 34. pp 21-39.

García, M. (2010). Transformaciones urbanas de León. Siglo XX. Tlacuilo, México D.F.

Harvey, D. (1989). La condición de la posmodernidad. Investigación sobre los orígenes del cambio cultural. Amorrortu: Buenos Aires.

Ibargüengoitia, J. (2005). Estas ruinas que ves. Booket: México D. F.

Lefebvre, H. (2013). La producción del espacio. Capitán Swing: Madrid.

Montero, J. (2014). El proceso de producción espacial en torno a la empresa del futbol en León, Guanajuato (1943-2014).Tesis para optar por el grado de Maestría. El Colegio de Michoacán: La Piedad.

Ortega, J. (2000). Los horizontes de la geografía. Ariel: Barcelona.

Santos, M. (1986). Espacio y método en Geocrítica, Año XII, núm. 65. Recuperado de: http://www.ub.edu/geocrit/geo65.htm

Torres, J. (1961). Guanajuato. Un hombre y un programa 1961-1967. Editorial Intercontinental: Guanajuato. 